\title{
Overview of MS Spasticity
}

\author{
Carlo Pozzilli \\ Sapienza University of Rome, Rome, Italy
}

\section{Key Words}

Multiple sclerosis · Spasticity · Symptoms · Burden ·

Management

Spasticity is one of the most frequent symptoms associated with MS and yet it is often overlooked and poorly managed. Possible reasons for this include the different understanding of the definition of spasticity, ranging from the exploratory rigidity perceived by a healthcare professional to the multiple related symptoms felt by patients, and also the different clinical assessment tools which do not always take into consideration the patient's perception of their disease. Another contributing factor is the limited effectiveness and tolerability profiles of most of the currently available agents [1]. A number of large studies have shown that spasticity produces some of the most common and disabling symptoms associated with MS, occurring in up to $80 \%$ of affected MS persons [2-4]. Between 30 and 50\% of MS patients rate their spasticity as moderate to severe [3], and some of the most commonly reported associated symptoms included rigidity, spasms, pain, worsening of movement difficulties and/or urinary dysfunction and sleep disturbances. The extent of the burden placed on MS patients who re- ported spasticity, compared with patients who did not experience spasticity, in terms of spasms, urinary dysfunction and sleep disturbances in a recent study is highlighted in table 1 [4].

The effect of spasticity on mobility is one of the most disabling changes associated with MS and it has a marked negative impact on patient well-being and quality of life [4-6]. It also increases the cost-burden associated with MS, with an increased need for physiotherapy and caregiver support [6]. Figure 1 highlights the strong correlation between worsening of spasticity and reduced walking ability.

While there is a clear impact of spasticity on the overall well-being of MS patients, the available evidence demonstrates a limited effectiveness of the classic first-line treatment options such as baclofen, tizanidine, gabapentin, and others $[1,6]$. Thus, there is an obvious unmet need for better therapeutic options for physicians and this is highlighted by the findings of a recent German survey which reported that in patients with moderate spasticity about $40 \%$ of physicians were unsatisfied or completely unsatisfied with current antispasticity therapies. In patients with severe MS spasticity about $60 \%$ of physicians were unsatisfied or completely unsatisfied with current treatments [6] (fig. 2).

\section{KARGER}

E-Mail karger@karger.com

www.karger.com/ene
(C) 2014 S. Karger AG, Basel

0014-3022/14/0717-0001\$39.50/0
Carlo Pozzilli

Department of Neurology and Psychiatry

Sapienza University, Viale dell'Università, 30

IT-00185 Rome (Italy)

E-Mail carlo.pozzilli@uniroma1.it 
Table 1. MS spasticity burden (data from [4]).

Fig. 1. Walking ability in patients with mild, moderate or severe spasticity [4-6].

\begin{tabular}{lcll}
\hline MS symptom & $\begin{array}{l}\text { No spasticity, } \\
\%\end{array}$ & $\begin{array}{l}\text { Spasticity, } \\
\%\end{array}$ & p value \\
\hline Daytime spasms & 5.4 & 67.1 & $<0.001$ \\
Urinary dysfunction & 29.2 & 70.4 & $<0.001$ \\
Sleep disturbances & 26.1 & 50.9 & $<0.001$ \\
$\quad$ Woken by urinary urgency ( $>$ 2 times/night) & 7.0 & 13.7 & $<0.001$ \\
Woken by spasms (one or more times/night) & 1.9 & 51.7 & $<0.001$ \\
\hline
\end{tabular}

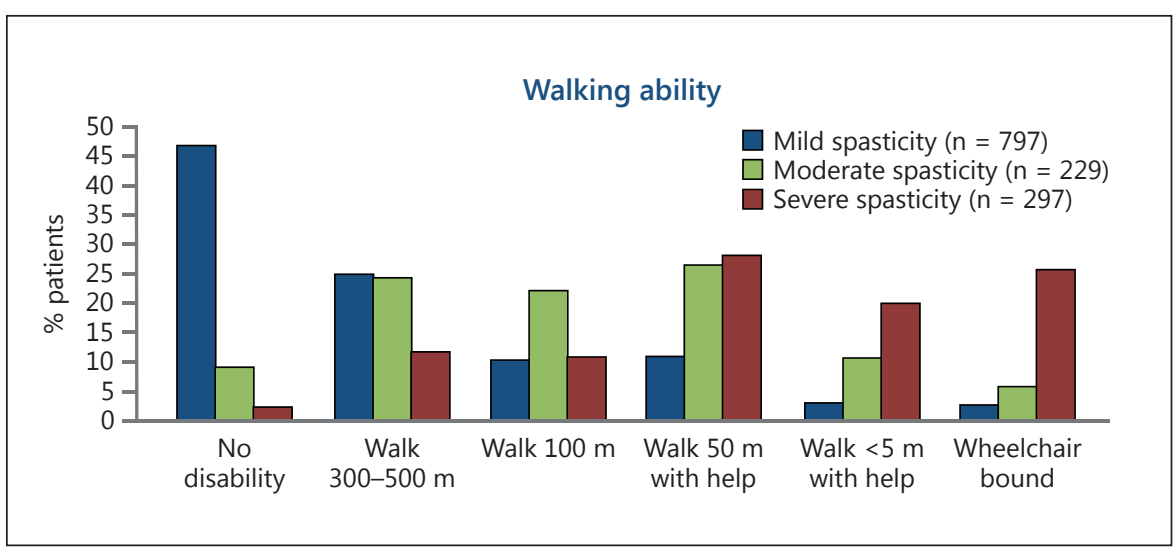

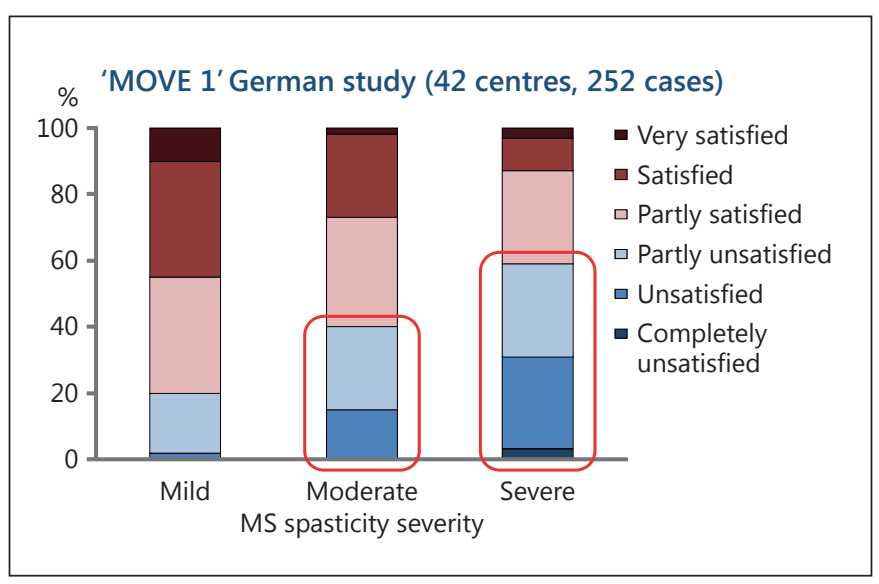

Fig. 2. Physicians' satisfaction with pharmacological treatment in patients with mild, moderate or severe MS spasticity (data from [6]).

New guidelines for the management of MS have been developed in Spain (fig. 3) [7] and Germany and both contain algorithms for managing MS spasticity [7]. Baclofen and tizanidine remain the first-line treatment options in both sets of guidelines for the management of generalised MS spasticity, and both recognise the role of the new THC:CBD oromucosal spray as a second-line op- tion for patients with moderate to severe treatment-resistant MS spasticity.

This supplement provides an insight into the latest clinical evidence concerning THC:CBD oromucosal spray $\left(\right.$ Sativex $\left.{ }^{\circledR}\right)$, a unique cannabinoid-based medicine comprising a 1:1 mixture of 9-delta-tetrahydocannabinol (THC) and cannabidiol (CBD). THC:CBD oromucosal spray acts as an endocannabinoid system modulator, and it is indicated as add-on treatment for symptom improvement in adult patients with moderate to severe spasticity due to multiple sclerosis (MS) who did not adequately respond to previous antispasticity therapy, and who demonstrated a clinically relevant response during a one month trial. At the present time, Sativex ${ }^{\circledR}$ is available in 17 European countries and it is also available in countries such as Australia, Canada and Kuwait.

\section{Conclusions}

Spasticity is one of the most common symptoms associated with MS, and in 30-50\% of the affected patients it is rated as moderate to severe. Symptoms include spasms, and worsening of pain, movement difficulties, sleep disturbances, urinary dysfunction and disability 


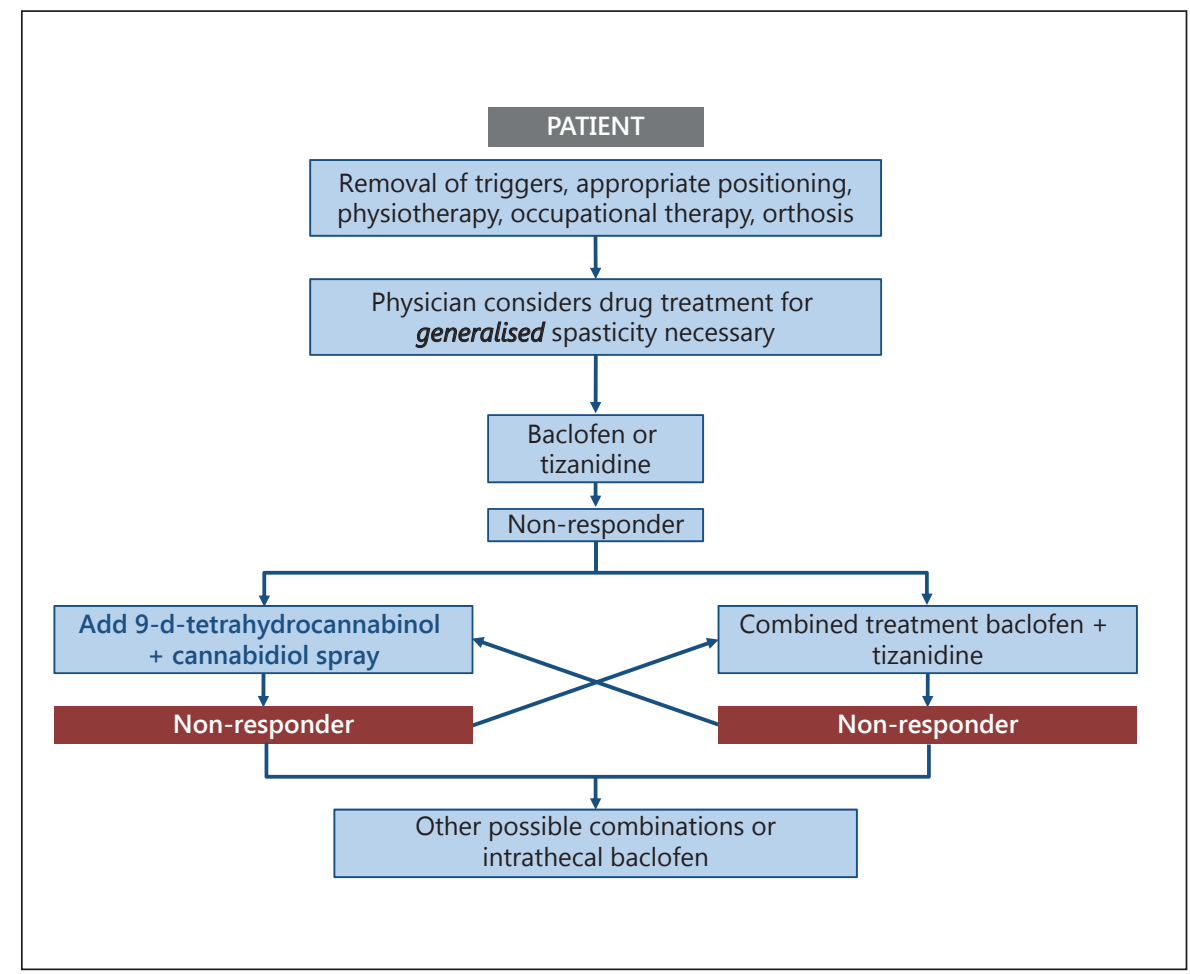

Fig. 3. Spanish guideline for the management of generalized MS spasticity (data from [7]).

and these result in an increased need for caregiver support, reduced well-being and quality of life, and an increased burden on families, friends and the healthcare system. There is a clear unmet need for more effective treatments and recent guidance recognizes the need for evidence-based support for the management of MS spasticity. Guidelines from Spain and Germany recommend baclofen and tizanidine as first-line options and acknowledge the available evidence supporting the use of THC:CBD oromucosal spray recommending it as a second-line option for patients with treatment-resistant spasticity.

\section{Disclosure Statement}

C. Pozzilli received an honorarium from Laboratorios Almirall, SA, for his participation in the Symposium and producing his article, which is included in this Supplement. He has no other relevant affiliations or financial involvement with any organization or entity with a financial interest in or financial conflict with the subject matter or materials discussed in the manuscript apart from those disclosed. Writing assistance was provided by Content Ed Net, with funding from Laboratorios Almirall, SA.

\section{References}

1 Shakespeare DT, Boggild M, Young C: Antispasticity agents for multiple sclerosis. Cochrane Database Syst Rev 2003;4:CD001332.

2 Hemmett L, Holmes J, Barnes M, Russell N: What drives quality of life in multiple sclerosis? QJM 2004;97:671-676.

3 Rizzo MA, Hadjimichael OC, Preiningerova J, Vollmer TL: Prevalence and treatment of spasticity reported by multiple sclerosis patients. Mult Scler 2004;10:589-595.
4 Oreja-Guevara C, González-Segura D, Vila C: Spasticity in multiple sclerosis: results of a Spanish patient survey. Int J Neurosci 2012; 123:400-408.

5 Arroyo R, Vila C, Clissold S: Retrospective observational study of the management of multiple sclerosis patients with resistant spasticity in Spain: the ' $5 E$ ' study. Expert Rev Pharmacoeconomics Outcomes Res 2011;11: 205-213.
6 Flachenecker P: A new multiple sclerosis spasticity treatment option: effect in everyday clinical practice and cost-effectiveness in Germany. Expert Rev Neurother 2013;13(suppl 1):15-19.

7 Oreja-Guevara C, Montalban X, de Andrés C, Casanova-Estruch B, Muñoz-García D, García I, Fernández Ó: [Consensus document on spasticity in patients with multiple sclerosis]. Rev Neurol 2013;57:358-373. 